\title{
Novel derivatization with Sanger's reagent (2,4-dinitrofluorobenzene [DNFB]) and related methodological developments for improved detection of amphetamine enantiomers by circular dichroism spectroscopy
}

\author{
H. Hegedüs ${ }^{1, *}$, A. Gergely ${ }^{1}$, T. Veress ${ }^{2}$ and P. Horváth ${ }^{1}$ \\ ${ }^{1}$ Semmelweis University, Institute of Pharmaceutical Chemistry, H-1092 Budapest, Högyes E. u 9., Hungary \\ ${ }^{2}$ Institute for Forensic Sciences, P.O. Box314/4, Budapest, H-1903, Hungary
}

\begin{abstract}
A new analytical procedure based on the derivatization of amphetamine with Sanger's reagent (2,4-dinitrofluorobenzene) and a subsequent circular dichroism spectroscopic analysis are proposed for the determination of amphetamine enantiomers. The main advantage of the approach is the fact that the new synthetized derivative can be detected in the visible wavelength region with significantly better sensitivity than the original amphetamine. This allows a reliable determination of the optical isomers of the amphetamine without the need of separation from some of the most frequently occurring additives such as caffeine and lactose in the case of illicit drugs, or auxiliary materials in the case of legal amphetamine containing preparations.
\end{abstract}

Key words. Amphetamine - circular dichroism - 2,4-dinitrofluorobenzene[DNFB] - derivatization.

\section{Introduction}

The majority of abused amphetamine preparations contains amphetamines produced clandestinely. The various production methods result in products with different qualities depending on the type of synthesis as well as on the chemicals used. The identification of by-products of the synthesis and the determination of the enantiomeric composition of the active substance as well as that of the impurities being present in the preparations, are important aims of the forensic or pharmacological analysis. Amphetamine profiling by the analysis of by-products and impurities were studied by several authors [1-4]. The enantiomeric analysis of amphetamine is also useful for both comparative purposes and the evaluation of the production method. The latter one is based on the analysis of the final product, either the pure enantiomer [5] or racemic mixture [6], depending on the synthetic route used for the production. Noggle and co-workers [7] studied the determination of enantiomeric composition of amphetamine prepared from norephedrine and norpseudoephedrine applying production of diastereomeric derivatives with $2,3,4,6$-tetra- 0 -acetyl- $\beta$-D-glucopyranosyl isothiocyanate (GITC) and subsequent HPLC separation on non-chiral phases. The derivatization of amphetamine was applied in order to improve the level of detection in HPLC analysis [8-11]. In the visible wavelength region more selective detection can be achieved than in the UV-range. The
Sanger's reagent (2,4-dinitrofluorobenzene[DNFB]) has been applied as a chromophore reactant in the analysis of primary and secondary amines forming a stable condensation product of high UV absorptivity [12-17].

In enantiomeric analysis, circular dichroism (CD) spectroscopy is a useful tool, even without the need of separation of the non-chiral matrix components $[18,19]$.

The amphetamine itself has rather weak CD-activity and even that occurs only in the less selective UV-region.

The aim of this study was to develop a derivatization procedure useful for the CD spectroscopic detection of amphetamine enantiomers in samples of forensic interests as well as in other areas of pharmacology. The optimum conditions of derivatization of amphetamine with Sanger's reagent was determined by designed and serial experiments. The applicability of the derivatization is demonstrated by analysis of samples modelling preparations encountered in various areas of pharmacology as well as in assumed procedures probably followed in laboratories supplying the black market.

The majority of illicit preparations contains racemic amphetamine, consequently, both isomers will appear in the biological fluids unchanged, while among the break-down products formed by the metabolism of most pharmaceutical drugs the appearance of pure amphetamine enantiomers can be expected. 


\section{Experimental}

\section{Materials}

The (-)amphetamine as base, the (+)amphetamine, $( \pm)$ amphetamine as sulphate salts, caffeine and lactose were obtained from Sigma Chemical Co. The 2,4-dinitrofluorobenzene (DNFB), derivatization agent was purchased from Fluka. LiChrosolve grade (Merck) of acetonitrile (MeCN), dioxane, tetrahydrofurane and methanol $(\mathrm{MeOH})$, synthesis grade of triethylamine (TEA) (Merck), analytical grade of borax (Merck) and double distilled water were used.

We have prepared sample modells containing: various amounts of (+)amphetamine sulphate or racemic amphetamine sulphate which were thoroughly homogenised with caffeine and lactose resulting in powders with $8 \%$ final concentration for caffeine and various concentrations for amphetamine, within the range of $5-30 \%$.

\section{Equipment}

\section{$C D$ and UV spectroscopic analysis}

Ellipticities and UV absorbencies were measured on a Jasco$720 \mathrm{CD} / \mathrm{ORD} / \mathrm{UV} / \mathrm{VIS}$ spectropolarimeter using cuvettes with optical lengths of $10 \mathrm{~cm}$ and $1 \mathrm{~cm}$, respectively.

Ellipticities were recorded in the ranges of $240-275 \mathrm{~nm}$ and $320-480 \mathrm{~nm}$ under thermostated circumstances. The temperature of the measuring cell was set to $25.0 \pm 0.2{ }^{\circ} \mathrm{C}$. UV and CD spectra were recorded in "Wavelength" mode and the discrete values of ellipticity and the absorbency in "Time" mode. The measurements in "Time" mode were carried out employing the following parameters: time for data registration, 5 min; resolution, $0.2 \mathrm{~s}$; accumulation, $1 x$; band width, $1.0 \mathrm{~nm}$; response, $4 \mathrm{~s}$; sensitivity, $50 \mathrm{mdeg}$. The wavelength mode parameters were as follows: sensitivity, 20 mdeg; resolution, $0.2 \mathrm{~s}$; accumulation, $3 x$; band width, $1.0 \mathrm{~nm}$; response, $2 \mathrm{~s}$; scan speed, $50 \mathrm{~nm} / \mathrm{min}$.

For the CD and UV spectroscopic analysis pure compounds dissolved in water or DNFB-derivatives being present in the reaction mixture were used as given below.

\section{GC/MS analysis}

For GC/MS analysis a Hewlett-Packard 5890 Series II gas chromatograph connected to a 5989A MS Engine mass spectrometer was used.

The gas chromatographic conditions were as follows: carrier gas, helium; column, HP-5 fused silica capillary (film thickness: $0.25 \mu \mathrm{m}) 15 \mathrm{~m} \times 0.25 \mathrm{~mm}$ I.D; injector temperature, $250{ }^{\circ} \mathrm{C}$; oven temperature program, $80{ }^{\circ} \mathrm{C}(2 \mathrm{~min})$, $20{ }^{\circ} \mathrm{C} / \mathrm{min}, 260{ }^{\circ} \mathrm{C}$ (10 min); MS interface temperature, $280{ }^{\circ} \mathrm{C}$; injection, $1 \mu \mathrm{L}$ of reaction mixture. Electron impact mass spectra were recorded in the $\mathrm{m} / \mathrm{z}$ range of $40-400$. The ion source temperature was $200{ }^{\circ} \mathrm{C}$.

\section{HPLC analysis}

The HPLC separation was carried out on a Shimadzu 10A chromatograph system with two LC-10AS pumps, a SIL10A autosampler and an SPD-M10 diodearray UV-detector. The chromatographic control and data handling was effected by CLASS-LC10 V 1.6 (Shimadzu) software. For the evaluation MS Excel 5.0 and Statistica 4.5 software packages were used.

The HPLC separation was done in reversed phase mode by using a mixture of acetonitrile-tetrahydrofuran- $0.1 \%$ triethylamine in water $(15: 15: 70 \mathrm{v} / \mathrm{v})$ at a flow rate of $1.5 \mathrm{~mL} / \mathrm{min}$ and a column $(25 \mathrm{~cm} \times 4 \mathrm{~mm}$ I.D. $)$ packed with chemically bonded octadecil silica (BST Rutin 10 C18, BST, Hungary). The chromatogram was monitored by UV detection at wavelength of $360 \mathrm{~nm}$. From the sample solutions volumes of $10 \mu \mathrm{L}$ were injected.

\section{Derivatization}

\section{Reagent}

$1 \mathrm{~mL}$ solutions of DNFB in $\mathrm{MeCN}\left(7 \times 10^{-2} \mathrm{~mol} / \mathrm{L}\right)$ were diluted, right before use to $10 \mathrm{~mL}$ with $2.5 \%$ aqueous solution of borax or mixture of TEA-MeCN $(5: 1000 \mathrm{v} / \mathrm{v})$.

Stock solutions of amphetamine were prepared in the concentration range of $5 \times 10^{-6}-6 \times 10^{-4} \mathrm{~mol} / \mathrm{L}$ by dissolving the sulphate salt in water or methanol.

\section{Study of the effect of the temperature and reaction time}

In order to study the effect of the temperature on the velocity of derivatization $0.6 \mathrm{~mL}$ of $10^{-5} \mathrm{~mol} / \mathrm{L}$ aqueous stock solutions of amphetamine were mixed with equal volumes of reagent solutions in $3 \mathrm{~mL}$ screw cap tubes and reacted at temperatures of $65^{\circ} \mathrm{C}, 45^{\circ} \mathrm{C}$ and $25^{\circ} \mathrm{C}$ for 60 minutes.

The reaction time needed for total conversion of amphetamine were determined by mixing of $0.6 \mathrm{~mL} 10^{-5} \mathrm{~mol} / \mathrm{L}$ aqueous stock solutions of amphetamine with equal volumes of reagent solution and then reacted in $3 \mathrm{~mL}$ screw cap tubes for various times in the range of 1-60 minute.

After derivatization reaction mixtures were cooled down to ambient temperature and diluted to $5.00 \mathrm{~mL}$ with acetonitrile or mixture of acetonitrile- $37 \% \mathrm{HCl}(99: 1 \mathrm{v} / \mathrm{v})$. The conversion was traced my GC/MS analysis of the reaction mixtures.

Blank solutions containing no amphetamine were also prepared by similar manners as described above.

\section{Study of the effects of solvent, type of base, molar excess of reagent being present in the reaction mixtures, and acidification after derivatization}

In order to determine the appropriate conditions of the derivatization procedure, the designed experiments were carried out applying two-level, eight-experiment designs according to the Plackett-Burman method [20,21]. On the 


\section{Original articles}

one hand, the set values of parameters were chosen as suggested in the literature $[12,14,16]$, and on the other hand, the conditions needed for the reliable HPLC analysis of reaction mixtures, such as miscibility of the reaction mixture with the mobile phase, usage of the same components in the reaction mixture as those being present in the mobile phase, etc., were also taken into consideration. Four parameters (solvent used for the preparation of amphetamine stock solutions, addition of hydrochloric acid after derivatization, molar ratio of the reagent to amphetamine, base applied in the reaction mixture) were selected to be examined. According to a previous study [16], the derivatization with Sanger's reagent is recommended in alkaline aqueous solutions followed by acidification of the reaction mixture with hydrochloric acid. The parameters and their set values are described in table I. The reaction mixtures were analysed by HPLC. The effects of factors were calculated by using the peak areas of the derivative. The experiments were evaluated graphically, by half-normal plotting of effects of factors, as applied previously [22].

\section{Determination of amphetamine in designed samples by $C D$ and UV spectroscopy after derivatization (experimental aspects)}

From the designed samples of amphetamine preparations containing (+)-amphetamine or racemic amphetamine at different concentration levels with lactose and $8 \%$ caffeine, $5 \mathrm{mg}$ amounts were weighted, and dissolved in $50 \mathrm{~mL}$ of water. From the aqueous sample solutions $0.6 \mathrm{~mL}$ aliquots were mixed with $0.6 \mathrm{ml}$ of TEA-containing reagent and thermostated to $65{ }^{\circ} \mathrm{C}$ for $40 \mathrm{~min}$. The ellipticities were measured at $425 \mathrm{~nm}$, the absorbencies were measured at $360 \mathrm{~nm}$. Calibrations were done by analysing known amounts of $(+)$ amphetamine and racemic amphetamine by the procedure described above. The (+)amphetamine content of samples was determined by both CD and UV spectroscopy, the racemic composition was determined by UV spectroscopy. Derivatized mixtures with known DNFB-amphetamine contents were diluted and analysed, where the amount resulted in signal to noise ratio equal to 3 was regarded the limit of detection

\section{Results}

\section{Derivatization}

The Sanger's reagent reacts with the amphetamine by forming the DNFB derivative and hydrogen fluoride, as shown
Table I. Optimized parameters and conditions in designed experiments.

\begin{tabular}{lcc}
\hline \multicolumn{1}{c}{ Parameter } & High level & Low level \\
\hline $\begin{array}{l}\text { Solvent of amphetamine } \\
\text { Addition of } 10 \mu \mathrm{L} \text { of } \mathrm{HCl} \text { to the reaction } \\
\text { mixture after derivatization }\end{array}$ & $\mathrm{MeOH}$ & $\mathrm{H}_{2} \mathrm{O}$ \\
$\begin{array}{l}\text { Base in the reaction mixture } \\
\text { Molar ratio of reagent to the amphetamine }\end{array}$ & TEA & Borax \\
\hline
\end{tabular}

in figure 1. In our experiments no detectable amounts of side-products were observed.

The velocities of the derivatization reaction at $25{ }^{\circ} \mathrm{C}$ and $45{ }^{\circ} \mathrm{C}$ were found to be rather slow because even after a reaction time of 60 minutes unreacted amphetamine could be identified by the GC/MS analysis of the reaction mixture. The derivatization at $65{ }^{\circ} \mathrm{C}$ temperature for $40 \mathrm{~min}$ and longer resulted in total conversion. A typical total ion chromatogram obtained by the analysis of a reaction mixture prepared at $65{ }^{\circ} \mathrm{C}$ for $40 \mathrm{~min}$, is shown in figure 2 . Amphetamine could not be detected in the reaction mixture that would appear at a retention time of $4.05 \mathrm{~min}$. The first peak in the total ion chromatogram refers to the excess of the DNFB, and the second peak belongs to the DNFBamphetamine derivative formed.

In figure 3 , the mass spectrum of derivative is shown where the molecular ion is also present at $\mathrm{m} / \mathrm{e}$ of 301 .

According to the results of designed experiments it could be stated that the derivatization with aqueous solutions of amphetamine sulphate resulted in significantly better conversion than with the methanolic solutions did. This results might be a consequence of the better solubility of the salt in water than in methanol. The conversion was notably higher in the presence of TEA than borax. No difference could be found between the rates of derivatization performed at various molar ratios of the reagent to the amphetamine, e.g. the two-fold excess of reagent resulted in the same conversion as did the four-fold. Although several authors suggested to acidify the reaction mixture, according to our results the addition of hydrochloric acid to the reaction mixture after derivatization did not affect the measurable amount of product. The application of hydrochloric acid is not advantageous because it might damage the equipment being in contact with it.<smiles>CC(Cc1ccc(-c2ccc([N+](=O)[O-])cc2)cc1)Nc1ccc([N+](=O)[O-])cc1[N+](=O)[O-]</smiles>

Fig. 1. Reaction of amphetamine with 2,4-dinitrofluorobenzene. 


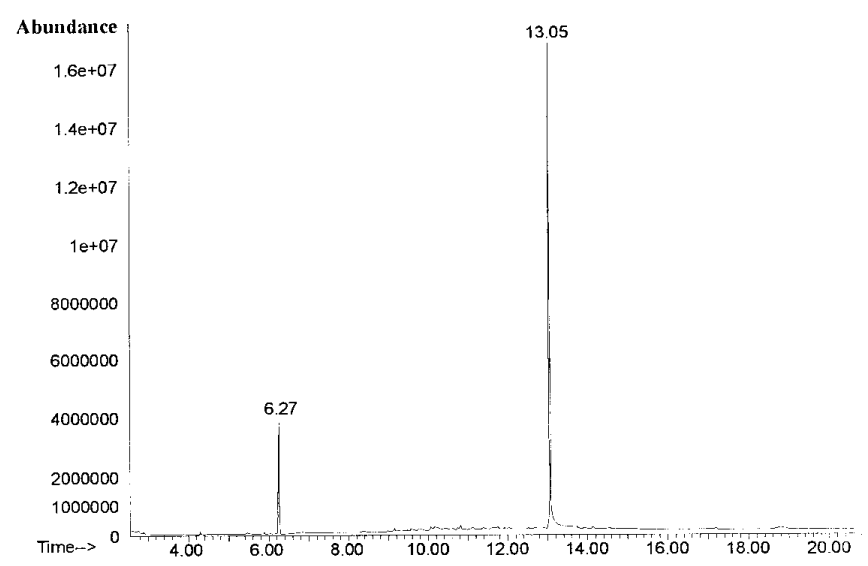

Fig. 2. A typical total ion chromatogram obtained by GC/MS analysis of a reaction mixture prepared at $65^{\circ} \mathrm{C}$ for 40 min. Peaks: 6.27 min - DNFB; 13.05 min amphetamine-DNFB derivative.

\section{$C D$ and UV spectroscopic analysis}

The CD spectrum of the (+)amphetamine in water recorded in the wavelength range of $240-275 \mathrm{~nm}$, is shown in figure 4 . The compound as well as its optical isomer has rather low molar ellipticity $\left([\Theta]\right.$; deg $\mathrm{cm}^{2}$ decimole $\left.{ }^{-1}\right)$. This is not advantageous for quantitative determination because of the low sensitivity. Above $275 \mathrm{~nm}$ the molar ellipticity of (+)amphetamine is so small that the compound is hardly detectable.

In figure 5, the $\mathrm{CD}$ spectrum of the (+)amphetamineDNFB derivative is shown in the wavelength range of $321-480 \mathrm{~nm}$. The molar ellipticity of the derivative is significantly higher than that of the amphetamine. At $425 \mathrm{~nm}$ maximum the molar ellipticity is nearly 9000. The derivative has ellipticity high enough in the low wavelength range $(240-275 \mathrm{~nm})$ but in this range the determination is less selective than in the visible region.

\section{Determination of amphetamine in designed samples by CD and UV spectroscopy after derivatization (result aspect)}

The dependence of both the ellipticity at $425 \mathrm{~nm}$ and UV absorbency at $360 \mathrm{~nm}$ on the concentration of amphetamineDNFB derivative was found to be linear in the concentration range of $5 \times 10^{-6}-6 \times 10^{-4} \mathrm{~mol} / \mathrm{l}$. The calculated parameters for calibrations according to $\mathrm{CD}$ and UV spectroscopic analysis are listed in table II. The limit of detection was 5.5 $\mu \mathrm{g}$ for $\mathrm{CD}$ spectroscopic and $3 \mu \mathrm{g}$ for $\mathrm{UV}$ spectroscopic analysis.

The quantitative results obtained for the analysis of amphetamine preparations are summarised in table III. A good agreement can be observed between the amphetamine concentrations set by spiking of mixtures of caffeine and lactose and the results obtained for the spiked samples after

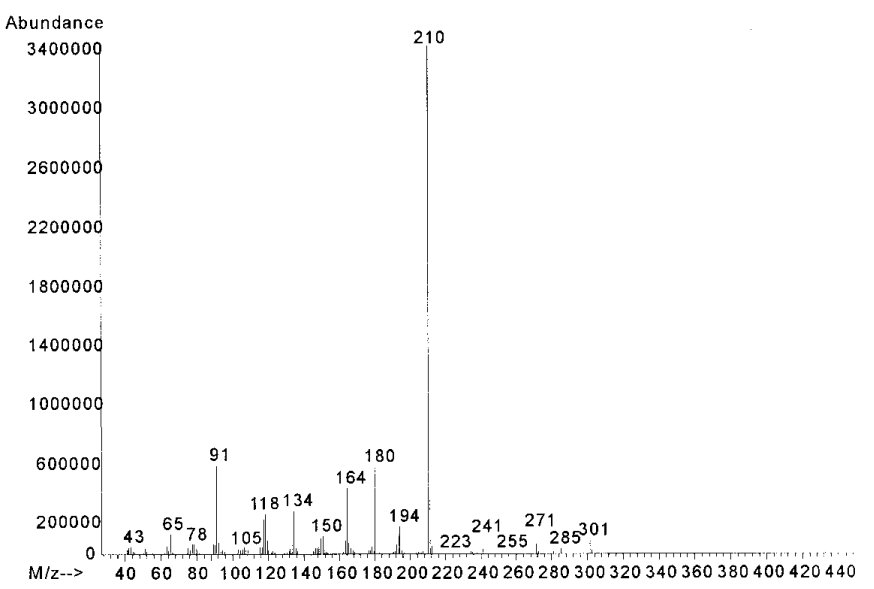

Fig. 3. Mass spectrum of the amphetamine-DNFB derivative.

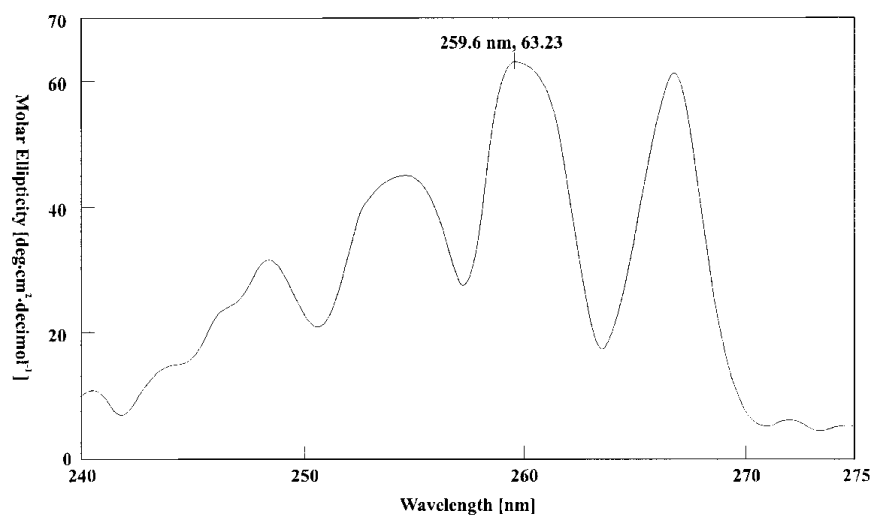

Fig. 4. Molar ellipticity spectrum of (+)amphetamine. Solvent: water; amphetamine concentration: $10^{-3} \mathrm{~mol} / \mathrm{L}$.

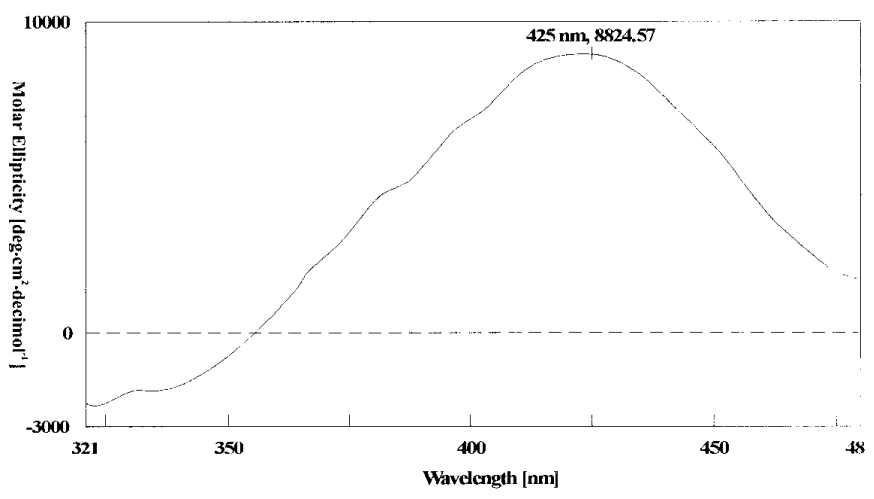

Fig. 5. Molar ellipticity spectrum of (+)amphetamine-DNFB derivative. Solvent: acetonitrile; amphetamine concentration: $6 \times$ $10^{-4} \mathrm{~mol} / \mathrm{L}$ 


\section{Original articles}

Table II. Calibration data for determination of amphetamine as DNFB-derivative by CD and UV spectroscopy.

\begin{tabular}{|c|c|c|c|c|}
\hline & \multicolumn{2}{|c|}{ CD spectroscopy at $425 \mathrm{~nm}$} & \multicolumn{2}{|c|}{$U V$ spectroscopy at $360 \mathrm{~nm}$} \\
\hline & $\begin{array}{c}(+) \text { amphetamine- } \\
\text { DNFB }\end{array}$ & $\begin{array}{c}\text { (-) amphetamine- } \\
D N F B\end{array}$ & $\begin{array}{c}(+) \text { amphetamine- } \\
\text { DNFB }\end{array}$ & $\begin{array}{c}\text { (-) amphetamine- } \\
D N F B\end{array}$ \\
\hline Slope (a) & 88354.1 & -87912.3 & 16874 & 16795 \\
\hline Intercept (b) & -0.26 & -0.15 & 0.11 & 0.09 \\
\hline $\begin{array}{l}\text { Regression } \\
\text { coefficient }\end{array}$ & 0.9998 & 0.9991 & 0.9997 & 0.9989 \\
\hline
\end{tabular}

Number of data pair:10. Type $\mathrm{I}=a \times C+b$. C: concentration [mol/L]. I: measured parameters (ellipticity or absorbance).

Table III. Determination of amphetamine content of preparations containing caffeine and lactose by CD and UV spectroscopy.

\begin{tabular}{|c|c|c|c|c|c|c|}
\hline \multirow{3}{*}{$\begin{array}{l}\text { Number } \\
\text { of samples }\end{array}$} & \multirow{3}{*}{ Amphetamine } & \multicolumn{3}{|c|}{ Amphetamine content of preparations (\%) } & \multirow{2}{*}{\multicolumn{2}{|c|}{ R.S.D. $* *(\%)$}} \\
\hline & & \multirow[t]{2}{*}{$\begin{array}{c}\text { Spiked } \\
\text { concentration }(\%)\end{array}$} & \multicolumn{2}{|c|}{$\begin{array}{c}\text { Measured } \\
\text { concentration (\%) } \\
\text { Spectroscopic method }\end{array}$} & & \\
\hline & & & $C D^{a}$ & $U V^{b}$ & $C D^{a}$ & $U V^{b}$ \\
\hline 1. & $(+)$ amphetamine & 5.22 & $5.14 \pm 0.14 *$ & $5.36 \pm 0.18^{*}$ & 2.72 & 3.36 \\
\hline 2. & & 11.18 & $11.02 \pm 0.28 *$ & $11.41 \pm 0.26^{*}$ & 2.54 & 2.28 \\
\hline 3. & & 18.25 & $18.43 \pm 0.35^{*}$ & $18.03 \pm 0.27 *$ & 1.90 & 1.50 \\
\hline 4. & & 25.49 & $25.66 \pm 0.30^{*}$ & $25.97 \pm 0.44 *$ & 1.17 & 1.69 \\
\hline 5. & & 30.33 & $29.99 \pm 0.43^{*}$ & $29.88 \pm 0.32 *$ & 1.43 & 1.07 \\
\hline 6. & $( \pm)$ amphetamine & 4.95 & - & $4.78 \pm 0.15^{*}$ & - & 3.14 \\
\hline 7. & & 15.47 & - & $15.02 \pm 0.20^{*}$ & - & 1.33 \\
\hline 8. & & 29.20 & - & $29.54 \pm 0.38 *$ & - & 1.29 \\
\hline
\end{tabular}

$*$ Standard deviation; No. of measurements $=7$. ** R.S.D.: Relative Standard Deviation. a Wavelength of measurement $\lambda=425$ nm. $b$ Wavelength of measurement $\lambda=360 \mathrm{~nm}$.

derivatization by $\mathrm{CD}$ and UV spectroscopic methods. For samples spiked with (+)amphetamine, quantitative results obtained by CD and UV spectroscopy are in good agreement with each other. The lactose did not disturb either the UV or $\mathrm{CD}$ spectroscopic determination of amphetamine because it does not have UV-absorbing chromophore and CD signal in the visible region applied during the measurements, even though it is an optically active compound. The caffeine is optically inactive and does not have UV absorbency at $360 \mathrm{~nm}$ where the quantification was effected. The standard deviation for $\mathrm{CD}$ and UV spectroscopic determination did not exceed $0.44 \%$.

\section{Conclusion}

The advantages of the derivatization of amphetamine with DNFB with respect to the CD spectroscopic analysis are as follows: the derivatization causes a significant $(\sim 150 \mathrm{~nm})$ batochromic shift, giving rise to a Cotton effect at $410-430$ $\mathrm{nm}$, and increases the molar ellipticity and the concomitant analytical sensitivity by two orders of magnitude; the parent compound (amphetamine) can be determined at $10^{-3} \mathrm{~mol} / \mathrm{L}$ concentration, whereas derivatization allows the analysis at as low concentration as $10^{-6} \mathrm{~mol} / \mathrm{L}$.

The proposed procedure is applicable for the analysis of preparations containing the amphetamine as pure enantiomer or one enantiomer of amphetamine in excess. The determination of amphetamine enantiomers in some cases might have practical significance in the analysis of biological fluids in order to interpret the origin of amphetamine being present in the organism, as well as in the study of general pharmaceutical products of intended or unintended amphetamine content, such as anorexigenic (e.g. chlorphentermine) or MAO-B blocking agents (e.g. selegiline) as well as illicit preparations.

\section{Acknowledgements}

This work has been supported by OTKA T 17570, MKM FKFP 1126/97 and NjM 447/96 grants. The valuable contribution of Ilona Matalin-Foór are highly appreciated. 


\section{References}

1. Kram, T. C. J. Pharm. Sci. 1977, 66(3), 443.

2. Noggle, F. T.; DeReuter, J.; Clark, C. R. Microgram 1994, XXVII(5),153-167.

3. Alm, S.; Bertler, C. Peak identification of impurity components in amphetamine and control of the analysing reproducibility. Abstracts of the Forensic Science Symposium; 1992 June 15-17; Linköping.

4. Kärkkäinen, M.; Sippola, E.; Pikkarainen, A. L.; Rautio, T.; Himberg, K. J. For. Sci. Int. 1994, 69, 55-64.

5. Rozwadowska, M. D. Tetrahedron Asymmetry 1993, 4(7), 1619-1624.

6. Allen, A.; Cantrell, T. S. J. For. Sci. Int. 1989, 42, 183-199.

7. Noggle, F. T.; DeReuter, J.; Clark, C. R. J. Chromatogr. Sci. 1987, 25, 38-42.

8. Mascher, H.; Göd, B.; Kikuta, C. J. Liq. Chrom. Rel. Technol. 1997, 20(5), 797-809.

9. Campíns-Falco, P.; Sevillano-Cabeza, A.; Molíns-Legua, C.; Kohlmann, M. J. Chromatogr. B. 1996, 687, 239-246.

10. Al-Dirbashi, O.; Kuroda, N.; Akiyama, S.; Nakashima, K. J. Chromatogr. B. 1997 695, 251-258.
11. Herráez-Hernández, R.; Campíns-Falco, P.; Sevillano-Cabeza, A. J. Chromatogr. Sci. 1997, 35, 169-175.

12. Pesez, M.; Bartos, J. Colorimetric and Fluorimetric Analysis of Organic Compounds and Drugs. New York, 1974; pp 128132.

13. Sanger, F. Biochem. 1945, 39, 507-515.

14. Lu, J.; Cwik, M.; Kanyok, T. J. Chromatogr. B. 1997, 695, 329-335.

15. Barends, D. M.; Blauw, J. S.; Mijnsbergen, C. W.; Gowers, C. J. L. R.; Hulshoff, A. J. Chromatogr. 1985, 322, 321-331.

16. Sacher, F.; Lenz, S.; Brauch, H. J. J. Chromatogr. A. 1997, 764, 85-93.

17. Brückner, H.; Gah, C. J. Chromatogr. 1991, 555, 81-95.

18. Purdie, N. Analytical applications of CD to the forensic, pharmaceutical, clinical, and food sciences. In Purdie N. and Brittain H. G. Ed., Analytical Applications of Circular Dichroism. Amsterdam: Elsevier, 1994, 241-278.

19. Gergely, A. J. Pharm. Biomed. Anal. 1989, 7, 523-541.

20. Plackett, R. L.; Burman, J. P. Biometrika 1946, 33, 305-25.

21. Heyden, Y. V.; Hartman, C.; Massart, D. L.; Michell, L.; Kiechle, P.; Erni, F. Anal. Chim. Acta 1995, 316, 15-26. 